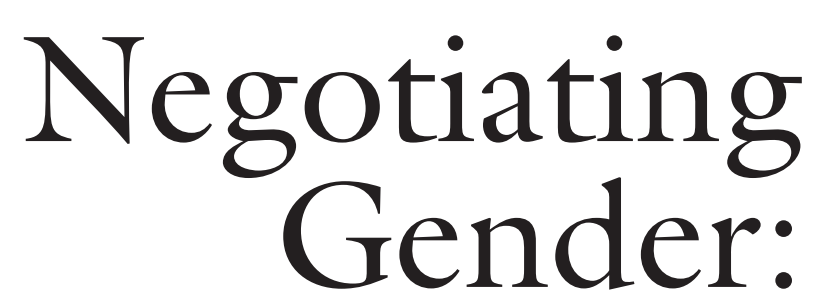

\title{
Female Combat Soldiers in Denmark
}

\section{By Stine Emilie Knudsen and Marie Sihm Teisen}

\section{Abstract}

Based on interviews with female combat soldiers, we explore what role conceptions of femininity and masculinity play for female Danish combat soldiers' experiences and behaviour in the military community. We find that female combat soldiers' status and ability to fulfil their potential as soldiers are determined by their capability to navigate expectations linked to their gender and their position as soldiers, respectively. Female combat soldiers must break down negative expectations linked to their gender while simultaneously and continuously navigating the limitations of forms of femininity accepted in the Danish Military.

\section{KEYWORDS}

Female soldier, gender, military, Danish Armed Forces, femininity 


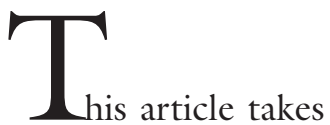
as its starting point the small group of Danish female combat soldiers who have been deployed to Afghanistan. In addition to being the only female soldiers among several hundred male colleagues in their deployment, they are also part of a larger, maledominated field: the Danish Defence. This organisation is, in addition to being an almost one-gendered organisation, also a clearly gendered organisation, meaning that the way a 'traditional soldier' is framed in this organisation is more or less synonymous with male bodies and notions of masculinity. Such framing draws on a long historical tradition, across many cultures, to associate war and soldiers with the male gender (see e.g. Donald 2001; Carreiras 2006; Connell 1995; Kronsell and Svedberg 2001). In his study of US naval officers, for instance, the American organisational researcher Frank Barrett (2001) shows that constructions of being a good soldier are connected to masculinity understood as physical strength, endurance, aggressiveness, a non-emotional logic and a non-complaining attitude. A similar picture emerges from a Norwegian study of soldiers in the Telemark Battalion, where traditional masculine ideals such as physical strength and endurance are presented as integrated parts of the soldiers' military selfimage (Totland 2009).

However, we cannot talk about the concept of masculinity without at the same time mentioning femininity and the different characteristics and practices with which the two are associated. Masculinity and femininity can be considered definitional opposite and mutually dependent concepts, as one cannot exist without the other. As Connell (1995) points out, cultures that do not believe men and women to be bearers of binary characteristics do not have a concept of masculinity like the one found in modern European and American cultures.
Due to this particular binary construction of masculinity and femininity in European cultural contexts, constructions of masculinity within the military institution are often synonymous with being physically strong and rational, whereas femininity is associated with being emotional and physically weak (Barrett 2001). The social construction of masculinity thus happens as a negation of the feminine, which is positioned as the opposite of the idealised soldier in Western militaries (Duncanson 2009). Downgrading the symbolic value of the feminine thus means that masculinity appears as a form of operative resource that women by definition do not have (Totland 2009). Female soldiers and women in combat uniforms may in that respect seem like a provocative antithesis to dominant discourses about femininity, masculinity, and the military; a dynamic which is likely to affect the well-being of women in the Danish Armed Forces

This contextual element notwithstanding, the plight of women in Western militaries has improved over the last decades (Ivarsson et al. 2005; Twenge 1997; Torres-Reyna and Shapiro 2002). ${ }^{1}$ The military institution is becoming gradually more inclusive and gender equal, also in the Danish context. In 1992 the Danish Armed Forces (whose organisation is called the Danish Defence) removed all restrictions on women's participation in the military, and women are now legally free to perform any military function. Nevertheless, the number of women employed in the military continues to be low. Even though there has been a significant increase in the number of young women signing up for compulsory military service (as a voluntary and negotiable employment), ${ }^{2}$ female military employees in the Danish Defence ${ }^{3}$ only make up 6.8 per cent ${ }^{4}$ of the total force (forpers.dk 2016). ${ }^{5}$ A study made in 2003 by the Royal Danish Defence College 
which explored this issue showed that every third woman employed in the Danish Defence had experienced sexually offensive behaviour at work (Øhrstrøm et al. 2003). ${ }^{6}$

Our study - and this article - supplements the above mentioned studies by exploring an important, though rarely studied, part of the Danish Defence with a focus on how notions of femininity and masculinity affect female soldiers' space for action and opportunities in the Danish Defence.

\section{MeTHOdOLOGiCAL CONSIDERATIONS}

This article is based on in-depth, qualitative interviews with nine female combat soldiers $^{7}$ who have trained with the Army combat troops 8 and therefore qualify to participate in land-based military operations. All the female combat soldiers we have interviewed are or have previously been employed in the Army and deployed to Afghanistan as combat soldiers. Female combat soldiers are particularly interesting in the context of this article, as women were not allowed to hold military positions in combat units until 1988 (Sløk-Andersen 2014), and in the period 2006-2014, only 719 out of 9228 soldiers deployed to Afghanistan were women. The interviewees represent various combat soldier functions and positions, which enables us to nuance their experiences and focus on where and why they differ.

The theoretical point of departure for the analysis is inspired by the Norwegian phenomenologist Toril Moi's perspective on the body as a fundamental starting point for the individual's experiences and views of the world. On this basis, we strive to adopt a dynamic view of the particular woman, where her gendered starting point is considered part of the reason for her particular experiences. At the same time, we focus on the interplay between the individual and the structural conditions. Here we look at when the bodily starting point of the individual becomes problematic, which tells us something about how women are perceived in a military context.

The intention is thus to identify areas in which female combat soldiers have limited options. To understand in more detail how such limitations occur, we make use of the theory of Zimmerman and West (1987), which helps us understand how actors handle and navigate gender in interplay with each other. From this conceptual perspective the meaning of the gender is the result of an endless line of trivial, routine actions performed by the individual, but assigned meaning in interplay with others and in the given context. The meaning of gender is thus a social and interpersonal phenomenon defined by collective agreement as to what constitutes femininity and masculinity, respectively, within the given cultural units. In this article the military community constitutes the cultural unit and thus the framework within which our interviewees act and interact.

As already mentioned, women in the Danish Defence constitute a minority. According to organisational theorist Rosabeth Kanter (1977), the dynamics created by a minority/majority situation can be understood through the concept of tokens. This concept refers to the symbolic status that minorities adopt and/or that may be imposed upon them. The concept of tokens is especially useful for understanding how the behaviour of female/feminine minorities is determined by their presence in a masculine and male-dominated organisation. According to Kanter, this token status means that the minority is highly visible and thus to a large extent is constantly being watched and judged. Another consequence is that the actions and performance of minorities are assessed on the basis of perceptions of their capabilities and behaviour, which in this case is related to their categorisation as women.

By combining the various theoretical 
concepts, we hope to be able to provide a more dynamic analysis that sheds light on the interviewees' space for action, development and conditions.

In the following we will explore in depth three main analytical focus points, which together and individually affect female soldiers' space for action and options. The first focus point concerns female soldiers' adaptation to the culture of the Danish Defence through the balancing of gender. The next focus point is visibility, where focus is on what it means that the gender of female soldiers differs from the one that dominates both statistically and culturally. Through the last focus point, performance pressure, we explore female soldiers' experiences of stereotypical ideas about what they as women are capable of.

\section{THE BALANCING OF GENDER}

The female soldiers we have interviewed repeatedly stress that they are women are not stopped by the idea that they do not belong in the military. Their stories, as well as our visits to several Danish barracks, made it clear to us both that they do not accept the idea that the military is reserved for men, and that their behaviour, in their opinion, challenges such ideas by their demonstration of physical strength, willpower, and that they are, in fact, 'one of the guys'.

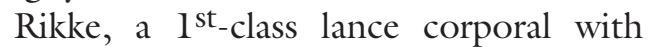
three deployments under her belt, is the first soldier to be interviewed. "I see myself as a solider and not as a woman when I put on these clothes", she tells us, referring to her military uniform, which qua its wellknown forest or desert camouflage and unisex-like cut makes it difficult to identify the gender of the person wearing it. But, as our interviews with the other female soldiers showed, soldiers are not 'made' by standardising the uniforms. Rather, these women were constantly forced to construct and adjust their gender identity if they wanted to be respected and recognised as competent soldiers. In particular, our study show how the female soldiers adopt two strategies as they strive to become part of the community: 1) adopting the masculine-connoted military culture and minimising female characteristics, and 2) situating and limiting their expression of what they consider to be their feminine side.

Most of the stories the women tell us about their place in the community concern the first mentioned strategy, namely how they as a matter of course accept the masculine-oriented culture, as they see it, and adopt anti-feminine behaviour. This can be related to West and Zimmerman's (1987) concept of gender displays, which is an elaboration of their concept of 'doing gender'. Gender displays refer to concrete, physical signs and actions that can be designated as either feminine or masculine in the particular context, and which thereby become a way for individuals to invoke a particular gender identity. In this context, the gender displays used by the female soldiers often resemble the ones they see among their male colleagues. Lea, a sergeant first class who has been deployed to Afghanistan once, tells us that she tries to become part of the community by using different gender displays which, in her experience, give her respect and recognition among her male colleagues:

"So I belched loudly - then of course they were like, 'ah, you rock!' (...) And then if you make some snappy remarks, just once in a while, then you gain their trust and respect in a different way" (Lea).

Several of the interviewees also find that by displaying what they consider to be masculine behaviour they become part of the group. Line, a lance corporal who have been deployed twice, experienced becoming 'one of the guys' when she, holding a forward command post, had to do repairs and maintain one of the large tracked vehicles - 
a task that requires both brute strength and getting your hands dirty. Line says:

"I was working down there, had oil on my hands, and I changed the tracks myself. So automatically I work alongside them and just become part of them. You just become one of the guys and we're all good friends. We're not girls and boys anymore; we are just together" (Line).

The women thus adopt parts of the masculine-connoted, military culture when displaying behaviour like belching, making snappy remarks and doing physically hard work requiring masculine standards for brute strength. The female soldiers assume and exercise these gender displays both elaborately and sometimes, as with the changing of the tracks, out of necessity; and they tell that it has a positive effect on their relation to their colleagues, as it to a larger extent makes them be seen as soldiers.

Another type of behaviour aimed at being a part of the group that the interviewed soldiers mentioned, was to minimise their female-connoted characteristics, e.g. hiding their body under loose clothes, wearing sports bras and abstaining from wearing make-up at work. Such identificatory displays', as Zimmerman and West (1987) understands physical artefacts with a gendered expression, are used here as concrete tools for navigating the military as a woman. For most female soldiers, not wearing something that may categorise them as too feminine is a conscious choice, as they experience being a woman as generally not an advantage in this context. Several of the interviewees find it important not to attract attention to their gender by wearing makeup, nail polish or similar. Line says:

"When deployed I do not think you should be wearing make-up, but of course you can have a ponytail, right, or put hair clips in your hair or whatever. You can also try to do your hair nicely, even though you are not wearing make-up. But when you are working as a combat soldier, then I think you should be neutral and nothing but that" (Line).

Later in the interview Line equates wearing make-up or other feminine-connoted identificatory displays with 'using your feminine side' to gain advantages. She explains that if women do this, they lose the respect of their colleagues. 'Neutral', in contrast, means minimising feminine-connoted identificatory displays. Most of the interviewees described any practising of feminine and female expressions as being in opposition to being a soldier. Line explains:

"Of course, you don't associate soldiers with people walking around wearing good-looking berets and make-up and so on (...). If you see someone look and act that way (...) then you will already have prejudged the person. You just don't do these things in this world" (Line).

Thus, in Line's experience, feminine-connoted identificatory displays are not respected in the combat troop. And her experience that it can cause a female soldier in the field to be prejudged if she is believed to be too preoccupied with her appearance is shared by the other women we interviewed. This awareness of the risk of being judged in the field is vital to how they choose to dress.

Most of the women we interviewed considered this situation a natural consequence of their employment in the military. As women, they were both newcomers to the military and a minority, and therefore they found it natural that they had to adjust. This leads us to a point made by Kanter, who has found that the minority will be the one that adjusts to the already established culture of masculinity. Despite the fact that these women are not stopped by notions that women do not belong in the military, they nevertheless practise an apparently accepted idea that true soldiers are masculine. 
Several studies of how women in uniform throughout the world handle masculine-connoted military cultures also conclude that most of these women practise strategies that involve adopting anti-feminine behaviour and imitating masculine military behaviour (see for instance Winslow and Dunn 2002; Sorin 2006; Sasson-Levy 2003; Carreiras 2006). Our study reveals a higher degree of complexity, though. The female soldiers do exercise parallel to their imitation of masculine military behaviour - a situated and limited performance of what they consider to be their feminine side. In other words, their adoption of masculine military behaviour is not all-encompassing, but context-dependent.

This is, among other things, evident from Lea's story of how she makes a conscious effort to separate her civilian identity from her military identity:

"There was LP, as I was called in the military, and then there was Lea, who was the feminine girl. At work I did not wear makeup, but I did use a lot of swear words. I was one of the guys. And when I came home, on Fridays, I put on nailpolish, makeup, all these kinds of things. I have just been 100 per cent conscious that I, personally, could not mix these two worlds, because I wanted to be one of them" (Lea).

Later in the interview Lea tells us that there is a delicate balance between being 'one of the guys' and maintaining your feminine side. Even though she deliberately left her feminine side at home, she could not allow for it to disappear altogether:

"Yes, because otherwise you are just repulsive [if you belch, fart, etc. too much]; of course you still want them to have this... you need to be slightly attractive, but not so much that they want to screw you all the time, that is" (Lea).

What Lea is describing here is an invisible boundary that can easily be crossed. Female soldiers must, as Lea says, 'be slightly attractive', but also, as she noted previously, 'make snappy remarks' to show that they are part of the group of guys. Several of the women feel that their ability to master the right balance between the two strategies affects their position as female soldiers in the military community. In line with this, a Swedish study shows that positive attitudes among men in the Swedish defence towards female colleagues are related to their view of these women's ability to adjust to the culture of the military organisation without losing their femininity (Ivarsson 2002). Similarly, negative attitudes towards women in the military are often caused by women who have adjusted too much, become too masculine without leaving any room for femininity (ibid.).

Because of their gender, female combat soldiers break with traditional, normative views of what constitutes a good soldier. This break means that the soldiers must work harder to prove that they are competent soldiers on an equal footing with their male colleagues. The female soldiers we talked to therefore adjust to the culture of the combat troop they are a part of by adopting what they consider masculine behaviour and downgrading their femininity. At the same time, they must be aware not to denounce their feminine side completely, as they must live up to normative perceptions of women and femininity.

\section{VISIBILITY}

Across the nine interviews one attitude in particular shone through. All the interviewees indicated that they did not want to receive special treatment of any kind. As Rikke said:

"I don't want to stand out from the rest. This is very important to me. I want to blend in" (Rikke). 
However, this is not always easy for female combat soldiers, who are often, whether they want to or not, the pink elephant in the room and thus impossible to miss.

Unwanted visibility is a main issue among our interviewees. The problems related to unwanted visibility can be related to Kanter's concept of tokenism, which is defined as the processes resulting whenever a group is skewed with a clearly definable subgroup. Kanter describes visibility as an interactional perceptual tendency leading to negative token dynamics. In her study of female employees in a heavily male-dominated organisation, Kanter points out that one of the consequences of being a token in a group is that your presence is highly visible. Visibility reflects the intense attention that is directed toward tokens, who always stand out among their colleagues and thus suffer exacerbated pressures to perform because their every step is being watched (Kanter 1977).

During our conversation on visibility we asked the interviewees whether they, as a consequence hereof, had ever received special treatment while active in the Danish Defence. This gave rise to two types of stories about two overall forms of special treatment or the more negative form of differential treatment within the system. There is, on the one hand, the regulated and institutionalised kind of special or differential treatment, such as gender-differentiated requirements and initiatives, and there is, on the other hand, the subtler kind, which is not always easy to pinpoint, but where women are faced with different demands and expectations than their male colleagues. With regard to regulated and institutionalised differential treatment there are, despite standardised admission requirements and expectations regarding the physical fitness of the individual soldier, examples of formal measures introduced to make it easier to be a woman in the Danish Defence, e.g. women's right to shower during their period. The women we inter- viewed express that this type of special treatment contributes to singling them out. As Belinda, a $1^{\text {st }}$-class lance corporal, says:

"If you're a woman you are allowed to shower every day [if you are having your period], but you shouldn't do it, because it is special treatment, and if there is anything the men don't like, it is special treatment" (Belinda).

Here Belinda underlines that female soldiers should be wary to accept special treatment, because it increases their visibility even more and underline that they are different from the majority. The combination of the female soldiers being evaluated and at the same time not performing at the same level as their male colleagues - which is how special treatment is understood means that they as a group are in risk of being labelled. Labelled as female soldiers who cannot perform under the current conditions. A main point to be drawn from this is that formal rules and well-meaning special treatment can lose their intended inclusive effect, as they may give rise to negative perceptions of the female soldiers.

In addition to well-meaning special treatment, the women also experience more negative kinds of informal differential treatment, e.g. when they, as Mette in the example below, are overlooked for jobs that are considered either too difficult or too hard for them. Mette says:

“I don't understand why they can't just ask. That is, if it is something heavy that needs carrying, I would find a way to carry it, and if not, I could just ask someone to help me. Sometimes its the idea that of course a girl can't do the job as well as a man, and I just think that is deeply ingrained in them" (Mette).

Here the reason why Mette feels overlooked at work is not invisibility but rather that she is too visible. Others view her as a woman who cannot carry heavy objects. Con- 
versely, the women experience that they are chosen for tasks where they have to use their communicative skills and keep several balls in the air, as many of them explain. It is their experience that they are better at these tasks than their male colleagues and they attribute this to their gender. For good or bad, the visibility of the female combat soldiers means that particular aspects of their professional competences are either overlooked or overemphasised, and that they are placed in the category 'woman' with the associations and capabilities that come with this category, rather than in the category 'soldier' with the relevant competences associated with this category.

\section{REPRESENTATIVES}

Several of the interviewees have felt that their individual actions affected the evaluation of female soldiers in general, and several also describe more implicitly that they act in ways that cause others to evaluate them positively as women. 'Token' means symbol or trophy, and an underlying point is here that tokens have difficulties being seen as individuals, but are to a larger extent considered representatives.

Ditte is one of the soldiers who talks about the experience of being a representative of a particular group - in this case female soldiers. She describes how she was subjected to sexist behaviour from some male Afghan soldiers during her deployment, and she had to report the incident to one of her superiors. In this case, not just the incident itself, but the entire situation and above all the fact that her gender had caused the problem made Ditte uncomfortable:

"You do not want to cause problems just because you are a woman. You see, there would not have been a problem in the first place if I had not been a woman" (Ditte).

The women in this way report that they feel responsible for showing that they as women can participate in war and do a good job without 'causing trouble'. They are determined not to cause trouble, and several also indicate that they balk at taking up certain issues, because they do not want to put female soldiers as a group in a bad light.

The Danish Defence operates according to a chain of command, which means that problems, when they arise, must be reported to one's superior; e.g. the regular soldiers go to their sergeant, who goes to their platoon leader. This means that a number of employees are involved, which, according to the interviewees, is not always seen as a good way of solving the problem, as this increases their own particular visibility and thus also the risk of undermining the reputation of female soldiers in general. As Ditte says in connection to a case concerning gender-discriminating behaviour to which she did not want to draw too much attention:

"It is best to solve things within your own ranks. Otherwise you risk setting a huge system into motion. Then everyone will know" (Ditte).

Solving things within one's own ranks means dealing with the matter among the regular soldiers without, for instance, involving the sergeant or platoon leader. This is not unique to female soldiers; during missions the easiest way to solve problems is to do so as they arise and among those facing them. However, for the women we have interviewed, the need to keep things within one's own ranks appears to be rooted in the more fundamental issue mentioned above, where one possible consequence of following the chain of command is to draw further attention to themselves as women and as someone 'causing' trouble because of their gender. The female soldiers in this way take it upon themselves that they are the ones causing trouble in complaint cases, not the colleagues that 
have treated them unjustly; and they avoid making such trouble, not just for their own sake, but for the sake of all women in the Danish Defence. As shown by e.g. Bloksgaard and Faber (2004) in their study of female police officers, similar experiences are also shared by women in other male-dominated professions. The fact that they by following the chain of command would draw further attention to themselves makes several of them choose not to report potentially problematic incidents.

All of our interviewees are very aware of when and how to take up the battle when faced with unjust or uncomfortable treatment. They know how to navigate this landscape of unwanted visibility, where stepping out of line can potentially end your career in the military. To our interviewees this is central to whether or not they will succeed in having a career in the Danish Defence. Line says:

"The [female] colleagues I've had who complained too much and claimed their rights are no longer employed in the Danish Defence.

And if they are, they have a very bad reputation. Once you have got a bad reputation, the Danish Defence is just the worst place to work. It will follow you everywhere" (Line).

The threat of being excluded from the community and from the Danish Defence altogether is the main explanation given for why the female soldiers choose not to report problems. In this context, Mette tells us about an episode where two male colleagues put their genitals in the face of Mette's female colleague, who was sleeping, and filmed her. Mette's colleague soon abandoned the idea of filing a complaint. As Mette explains: "Well, once you choose to make a case out of it, that is what you will be known for". Line also tells us about a friend who was threatened by a male colleague, who told her that:

“She shouldn't walk around alone in
Afghanistan, because you never knew what could happen when you were a single girl surrounded by so many men" (Line).

According to Line, her friend "was the type who could not keep her mouth shut", which meant that she filed a complaint which resulted in her being seen as the problem of the platoon, leading to her demobilisation after having spent only three weeks in Afghanistan. Although these stories are not their own personal stories but involve friends and acquaintances of the interviewees, they paint a picture of the culture in which these situations arise and act as instructive examples teaching our interviewees how to behave if they want to do well. Furthermore, through the examples the interviewees present themselves as women who are able to 'keep their mouths shut' and who know when to put their foot down and when to grin and bear it - qualities that seem essential to them.

The women who fail to keep quiet, in contrast, may come to feel the consequences. Here Line talks about female soldiers who complain about unjust treatment:

“Then they've complained a bit too much or they've felt violated and they have stood their ground. Of course you should stand your ground if you feel you have been violated, I see that, but you should also expect that when you turn something into a case, then you risk being forced to leave the Danish Defence, because the rest of your future is ruined" (Line).

As evident from the above, the consequences of standing out - of complaining are, according to the interviewees, so serious that this appears to be good reason to not report incidents to their superior or at all.

However, deliberations relating to visibility alone do not determine what our interviewees regard as good cause for com- 
plaint or as something others should be called to account for. With regard to gender-discriminating language, Mette says:

"When you choose a profession like the Danish Defence I think you should think about what you make of it. Not that you should tolerate everything, but in my opinion there's no point in being too prissy. That is, some things you just have to grin and bear" (Mette).

In line with this view, Rikke says the following about the culture of the Danish Defence:

"I would call it soldiers' jokes or garage humour, right, which involves everyone, and if you can't handle it, well then ... That is, we live in a male-dominated world here in the Danish Defence, and of course we will just have to ... It can't all be flowers and pink clouds" (Rikke).

Both Rikke and Mette are of the opinion that their male colleagues' slightly coarse "soldiers' jokes" are part of working in the military. All the interviewees have reflected on the language and decided how to act in and with it. Therefore, such statements may reveal that the interviewees really have accepted the language or that they have been forced to accept it as part of the job.

Some of the interviewees do put their foot down when faced with behaviour that is unacceptable to them. Rikke, for example, explains that she is very aware of her boundaries and that she lets her colleagues know when they cross them:

"If you can tell that this person will just go on and on and that this causes him to have a negative relation to the women. Then you have to talk to him and let him know that it is not okay" (Rikke).

Several of the other women support this approach. In her $\mathrm{PhD}$ thesis on gender bar- riers in the Swedish military, Alma Persson has found that the majority of the women who hold leadership positions have rejected the 'put up with everything' approach that dominated when they first arrived in the military in favour of a more critical approach, where they put their foot down and criticise the organisation when necessary (Persson 2011). This observation can be related to our study, as the women who have done well in the Danish Defence are those who have managed to find the balance between not being 'prissy' and still being able to put their foot down when it matters.

\section{Performance Pressure}

In addition to their status as tokens, which affects their attitude towards differential and special treatment and how they deal with sexist behaviour, the women's minority position also affects their physical training. All the women we interviewed tell us that they are very aware of the importance of living up to the physical requirements. The female soldiers find their physique to cause more problems than their male colleagues, and they therefore feel forced to work harder to be able to deliver the same performance. This awareness of how they represent themselves cause the women to overcompensate by making an extra effort and by making sure they are among the best. This enables them to handle their visibility and the initial scepticism they feel is directed towards female soldiers. Here Line tells us how she, when deployed to Afghanistan, had to be extremely aware not to give anyone cause to think that she was not able to do her job. She explains:

“They've been very impressed, also in Afghanistan. Very impressed that I've been able to keep up without complaining, especially because the guys complained, you see. That is quite normal, right. But I've always run the same distance they have, carried the 
same load they have, marched for as long as they have" (Line).

Here Line indicates that she has worked just as hard as her male colleagues and, in her opinion, more so, and that she has done so without complaining. Rikke also talks about her expectations for herself:

"I have extremely high expectations for myself, because I would rather be in the good end of the spectrum than in the bad end. Because if you are in the bad end, then it's because I'm a girl and can't handle it. (...) And if I'm in the good end, well then ... then nothing. 'Oh, that one, she is tough enough' (...). That is, you need to be in the good end, and you need to do the extra work to keep up" (Rikke).

In both examples Line and Rikke are part of an environment considered natural to the male soldiers, whereas the female soldiers do not feel that they fit and therefore are unable to keep up, regardless of their actual qualifications. Here only the men are allowed to be at a comfortable intermediate level. The men are allowed to remain invisible, whereas the women are constantly visible, constantly judged and judged harder than the men. Therefore, if they are at an intermediate level they will be considered less competent than their male colleagues at the same level. Due to their visibility, the female soldiers often have to work twice as hard if they want their colleagues to recognise their work. Clearly, their motivation for working extra hard on their physique is not so much a wish to meet the obligations and demands of the job regarding physical strength as it is a wish to overcome stereotypical ideas of what women are capable of. It is important here to note that the female combat soldiers appear to feel that this performance pressure may change with time. For example, Belinda tells us that she only focusses on completing the training course now: "As long as I pass my tests, I am hap- py". Even though the women relate to their training pressure differently, they all tell us that it has been important for them to do well, that they have all had to go the extra mile at the start of their career. This may be related to the fact that the women we have interviewed can be considered successful - they are the ones who have completed both compulsory military service, the training and more. In other words, they are talented and competent women who feel that they have managed to gain respect and recognition during their time in the Danish Defence. If they are able to relax a bit with regard to physical training it may be a result of what Ditte describes as their seal of approval: "I have already been rubber-stamped, because I have been deployed". There is thus a lot to suggest that experience and time cause the women to become more conversant with their colleagues, obtain recognition and reduce their visibility. With time and as they gain seniority, their gender may thus become a less relevant issue.

\section{CONCLUSION}

The female soldiers we have spoken to all indicate that they, during their time in the Danish Defence, have had to find a balance between expressing themselves not just in feminine as well as masculine ways, but also in acceptable feminine ways. This gender balance seems to be of great importance to the women's social as well as professional standing, both in regards to how they view themselves and to how their colleagues view them.

Such expectations regarding their behaviour to a large extent determine their options, which may be particularly clear in connection with physical training, where they need to over-perform, and in connection with gender-related issues, such as being exposed to sexist behaviour, where they are more inclined to remain silent to avoid increasing their visibility. In our interviews 
with the women, we see that as time goes by they obtain a form of social and professional seniority that makes it easier for them to navigate the invisible, gendered 'code of conduct' while their colleagues get used to their presence, so to speak. Initially, however, female soldiers arrive at an environment that does not recognise or reward their contribution, which means that their chances of behaving and advancing as soldiers are limited and depend on their own ability to adapt.

In this article we have shed light on and provided a voice to an, in research at least, often invisible group within the Danish military. As well as providing insights to this field, we also open up for new research questions, that remain unanswered, but which would be highly interesting to pursue further. For example, it is evident that rank and military experience, and not only gender, shape the female soldiers' experiences and possibilities. Both the role and limits of seniority and rank in relation to gender could indeed be further explored. Another important area to explore further could be gender issues within compulsory military service, where the participants have neither rank nor experience to lean on to. Or, conversely, since there are only very few women in leading positions, this might provide an opportunity to explore if there is a limit to the possibilities available, even for high performing women in the defence. These open questions will have to stand unresolved, for now, but underline the fact that much more research is needed within this field.

\section{Notes}

1. Ivarsson et al. (2005) find indications that male officers' attitudes towards women in the military do not differ between countries and cultures, but estimate that military organisations share universal values and traditions that tend to favour men over women.
2. Women are not subjected to compulsory military service, but have a right to undertake compulsory military service on equal terms with male conscripts. Women can choose to be employed on terms resembling those of male con-scripts, but are not bound by their employment and can choose to resign at any time.

3. The Danish Defence thus distin-guishes between military employees and civilian employees. Civilian employees represent just over 20 per cent and include e.g. electricians, mechanics, cooks, doctors, pedagogues, engineers, journalists and IT specialists.

4. The figures represent female military employees under Defence Command Denmark and the four agencies: the Danish Ministry of Defence Estate Agency, the Danish Ministry of Defence Accounting Agency, the Danish Ministry of Defence Acquisition and Logistics Organisation and the Danish Ministry of Defence Personnel Agency. Conscripts are not included in the study (forpers.dk).

5. In 2004 the share was 2.6 per cent, but in 2012 and 2013 it had increased to 17.9 and 19.3 per cent, respectively. The high number of women doing compulsory military service in 2013 is a result of the 2013 agreement for the Danish Defence. In 2013 the number of available positions was reduced by approx. 800 , which meant that agreements that had already been made were transferred to 2014. As the majority of those transferred were men, the share of women is higher than in the previous year (forpers.dk).

6. In the wake of the report from 2003 the Danish Defence launched several initiatives aimed to restrain gender-discriminating behaviour. Nevertheless, the share of women who choose to pursue a career in the Danish Defence, but leave the military before completing compulsory military service continues to be large.

7. The criterion for being a combat soldier may vary, as the weighting of the concrete tasks performed during deployment may differ. Formally, it is the educational background of a soldier that allows her to call herself a combat soldier; this is also the criterion used here. Before soldiers can be deployed as professional soldiers, they must have trained as combat soldiers. The Army Reaction Force is the training offering the most direct path to deployment. 


\section{REFERENCES}

- Barrett, F. J. 2001. The Organizational Construction of Hegemonic Masculinity: The Case of the US Navy. In: Whitehead, S. M. and Barrett, F. eds. The Masculinities Reader. Cambridge: Polity Press. - Bloksgaard, L. and Brock Faber, S. 2004. Køn på arbjede - En kvalitativ undersogelse af mandlige sygeplejerskers og kvindelige politibetjentes arbejdesliv. Aalborg: Aalborg University Press.

- Carreiras, H. 2006. Gender and the Military: Women in the Armed Forces of Western Democracies. Routledge Military Studies series. London: Routledge.

. Connell, R. W. 1995. Masculinities. Cambridge: Polity Press.

- Donald, R. R. 2001. Masculinity and Machismo in Hollywood's War Films. In: Whitehead, S. M. and Barrett, F. eds. The Masculinity Reader. Cambridge: Polity Press.

- Duncanson, C. 2009. Forces for good? Narratives of military masculinity in peacekeeping operations. International Feminist Journal of Politics. $11(1), 63-80$.

- forpers.dk. 2016. Kvinder i forsvaret. [Online]. [Accessed 17/02/2016]. Available from: http:// forpers.dk/hr/Pages/KvinderiForsvaret.aspx. - Ipsen, S. and Malmgren, M. 2000. Seksuel chikane-holdninger og erfaringer blandt KADs tillidsvalgt. Casa.

- Ivarsson, S., Estrada, A. X., and Berggren, A. W. 2005. Understanding Men's Attitudes Toward Women in the Swedish Armed Forces. Military Psychology. 4(17).

- Kanter, R. M. 1977. Men and Women of the Corporation. New York: Basic Books.
- Kronsell, A. and Svedberg, E. 2001. The Duty to Protect: Gender in the Swedish Practice of Conscription. Cooperation and Conflict: 153-176.

- Moi, T. 1999. What is a woman. Oxford: Oxford University Press.

- Persson, A. 2011. Changing boundaries, defending boundaries. Gender relations in the Swedish Armed Forces. Thesis. Linköping Studies in Arts and Science.

. Sorin, K. 2006. Women in the French Forces: Integration versus Conflict. In: Pinch, F. C. et al. eds. Challenge and Change in the Military: Gender and Diversity Issues. Winnipeg: Wing, 76-96.

. Torres-Reyna, O. and Shapiro, R. Y. 2002. Women and sexual orientation in the military. Public Opinion Quarterly. 66.

- Totland, O. M. 2009. Det operative fellesskapet. En sosialantropologish studie av kropp, kjønn og identitet blant norske soldater $i$ Telemark Bataljon. Masteroppgave i sosialantropologi. Department of Social Anthropology, University of Oslo.

- Twenge, J. M. 1997. Attitudes toward women 1970-1995: A meta-analysis. Psychology of Women Quarterly. 21(1).

-Winslow, D. and Dunn, J. 2002. Women in the Canadian Forces: Between Legal and Social Integration. Current Sociology. 50(5), 641-667.

- Zimmerman, D. and West, C. 1987. Doing Gender. Gender er Society. 6.

- Øhrstrøm, B., Eriksen, J., and Knudsen, L. 2003. Undersogelse af forekomst og oplevelse af konskrankende adfard $i$ Forsvaret. Hovedresultater. Copenhagen: Royal Danish Defence College. 